Article

\title{
Exploring Shopper's Browsing Behavior and Attention Level with an EEG Biosensor Cap
}

\author{
Dong-Her Shih ${ }^{1, * \mathbb{C}}$, Kuan-Chu Lu ${ }^{1}$ and Po-Yuan Shih ${ }^{2}$ \\ 1 Department of Information Management, National Yunlin University of Science and Technology, Douliou, \\ Yunlin 64002, Taiwan; qq1214x@yahoo.com.tw \\ 2 Department of Finance, National Yunlin University of Science and Technology, Douliou, \\ Yunlin 64002, Taiwan; D10424003@yuntech.edu.tw \\ * Correspondence: shihdh@yuntech.edu.tw; Tel.: +886-932-690178
}

Received: 12 October 2019; Accepted: 29 October 2019; Published: 31 October 2019

\begin{abstract}
The online shopping market is developing rapidly, meaning that it is important for retailers and manufacturers to understand how consumers behave online compared to when in brick-and-mortar stores. Retailers want consumers to spend time shopping, browsing, and searching for products in the hope a purchase is made. On the other hand, consumers may want to restrict their duration of stay on websites due to perceived risk of loss of time or convenience. This phenomenon underlies the need to reduce the duration of consumer stay (namely, time pressure) on websites. In this paper, the browsing behavior and attention span of shoppers engaging in online shopping under time pressure were investigated. The attention and meditation level are measured by an electroencephalogram (EEG) biosensor cap. The results indicated that when under time pressure shoppers engaging in online shopping are less attentive. Thus, marketers may need to find strategies to increase a shopper's attention. Shoppers unfamiliar with product catalogs on shopping websites are less attentive, therefore marketers should adopt an interesting style for product catalogs to hold a shopper's attention. We discuss our findings and outline their business implications.
\end{abstract}

Keywords: consumer behavior; electroencephalogram (EEG) biosensor; attention and meditation; brain computer interface

\section{Introduction}

E-commerce, which has grown exponentially because of Internet technology, has induced changes at the market, industry, and economic levels, and has profoundly altered life, politics, and society [1]. Online network platforms are used globally to undertake various online services, and such platforms provide a robust means for generating income and, for an immeasurable number of consumers from around the world, to shop online [2]. Shopping websites display numerous products organized by category; despite being produced by different firms, and many of these products share similar features. However, these products, along with their information, are too great in number to be processed by the human brain because of a human's limited cognitive capacity, thus causing the consumer confusion and low satisfaction [3-5]. In addition, shopping is a series of decision-making processes aimed at satisfying consumer needs. The focus of academic attention should be shifted to online shopping behavior because of the mismatch between excessive stimuli and limited brain capacity [6]. According to Drucker [7], "the objective of a business is to create and retain customers". Information about customers largely concerns their consumption behavior, which involves the processing and selection of product information.

Generally, retailers want consumers to spend more time shopping, browsing, and searching for products in the hope that they make a purchase. On the other hand, consumers may want to restrict their 
duration of stay on websites due to a perceived risk of loss of time or convenience [8]. Previous research discussing the purchasing decision process has assumed that shoppers face time pressure. For example, Lin and $\mathrm{Wu}[9]$ found that time pressure will increase the proportion of consumers unable to make a judgment or a choice. Vermeir and Kenhove [10] suggested that consumers under high time pressure search less for coupons and products with a promotion. Rieskamp and Hoffrage [11] demonstrate that compared to those under low time pressure, individuals under high time pressure accelerate the search for information, using less information, and staying focused on the most important features. Liu et al. [12] indicate that when shopping online under time pressure, participants' observation length and count for browsing products with high brand awareness were respectively longer and higher than those for browsing products with low brand awareness. However, when they shopped online without time pressure, no difference between products with high and low brand awareness levels was observed.

Time pressure is an essential variable of consumer behavior; it prompts a decision to be made within a limited time [13]. Moon and Lee [14] perceived time-pressure purchases as a consumption decision made within time constraints specified by the consumer, suggesting that time pressure indicates a sense of psychological urgency. Moreover, consumers typically base their purchasing decisions more on limited knowledge than on careful deliberation and comparison; such decisions tend to be made in a matter of seconds [15-17]. Pieters and Warlop [18] showed that time pressure affects visual attention in ways such that consumers skip certain brand elements to optimize their decision-making. Moreover, both the cue utilization model proposed by Olson and Jacoby [19] and the theory of planned behavior proposed by Ajzen [20] assume that consumers are aware of their purchase motives and can distinguish products and brands they intend to purchase. Thus, some consumers have selection criteria that form a basis for evaluating product brands and selecting the top-ranked ones.

Shoppers behavior online has been reported in many studies, and the browsing behavior and attention span of shoppers engaging in online shopping under time pressure were investigated in the present study. The remainder of this paper is structured as follows. Section 2 reviews relevant literature and describes hypotheses about online shopping behavior. Section 3 introduces the method of this study. The findings are presented in Section 4 and their implications and suggestions are discussed in Section 5. Finally, Section 6 concludes this study and outlines this paper's contributions.

\section{Background and Hypotheses}

Time pressure is an influential factor in consumer behavior [21]; it can have a marked influence on decision-making and restrict information-processing ability [22]. Its effects on people's decision making intensify in the face of information overload [23]. Moreover, Payne et al. [24] found that people progress through a hierarchy of responses as time pressure intensifies. Specifically, shoppers under moderate time pressure become faster and slightly more selective at information processing, whereas those under heavy pressure tend to skim through information superficially without examining every single detail. However, some studies have suggested that time pressure typically prompts decision makers to make decisions and execute decision-making strategies through simple means $[25,26]$, and that people under time constraints can turn to other strategies to facilitate their information processing [27]. In addition, Levy [28] showed that when people were in a hurry, they hastened their decision making. Pieters and Warlop [18] argued that consumers under time pressure will filter some information, accelerate information acquisition, and adjust their information acquisition strategies.

Generally, time pressure reduces visual attention [29]. Although products with newly designed packaging can attract visual attention [30], such products can be neglected by people who perceive their packaging to be overly novel [31], leading to financial loss and even the removal of some products from the shelf [32].

Clement et al. [6] noted that consumers under time pressure tend to focus on certain products and brands, as well as their characteristics. Studies conducted in brick-and-mortar stores have found that the timing of purchases made under time pressure is similar to those made when not under time 
pressure. This indicates that consumers do not select certain products due to time pressure; they either make decisions in a matter of seconds when they need to identify familiar information quickly from a pool of information [33], or adjust their search strategies to concentrate on the design features of brands [18]. Accordingly, this study argues that shoppers under time pressure focus on fewer products to facilitate their product search on shopping websites, and that they adjust their search strategies to identify the salient design features of products; this information-processing strategy reflects the stimulation of the brain in a top-down fashion. Based on the aforementioned argument, Hypotheses 1 and 2 were formulated as follows:

Hypotheses (H1). Shoppers view fewer products when shopping under time pressure than they would when shopping not under time pressure.

Hypotheses (H2). Shoppers focus more on renowned brands when shopping under time pressure than they would when shopping under no time pressure.

Our ability to focus on the task at hand is a key element in efficient information processing and our attention is easily distracted by novel events or changes in the stimulus environment [34]. Bettman et al. [35] maintained that attention changes occur because of reflexive reactions to threats such as time pressure. In a study by Ordonez and Benson [27], subjects dealing with decisions under time pressure adopted different decision-making strategies to accelerate their information-processing speed. Zur and Breznitz [36] also argued that decision makers typically spend less time viewing information when they are under time pressure, indicating that under such circumstances they may change their decision-making strategies and thereby change their level of attention. Therefore, Hypothesis 3 was formulated as follows:

Hypotheses (H3). Under time pressure, shoppers engaging in online shopping are less attentive than those not under time pressure.

In the United Kingdom, approximately $70 \%$ of consumers who enter grocery stores have incomplete purchase intentions [37]. Previous research [38] has shown that $85 \%$ of consumers do not handle commodity items while shopping and $90 \%$ of consumers view only the covers of commodity items. Furthermore, consumers tend to purchase products they like after simply viewing them; such actions occur most frequently during online shopping [39]. Brands with sophisticated designs and noticeable visual elements (e.g., product names, logos, layouts, and slogans) can make a deep impression on consumers [40-42].

From a cognitive neuropsychological perspective, visual attention can be expressed in terms of orientation-attention and discover-attention. Orientation-attention is a parallel and non-selective pre-attentive search process that enables a considerable amount of information to be processed efficiently and simultaneously. Discover-attention is a serial search process of sequentially searching for information details on the packaging of a product (e.g., textual content and caution labels). In the view of Perkins [43], orientation-attention is the primitive stage of attention, whereas discover-attention enables the complete understanding of a commodity. Neither cognitive system can be distinguished easily in real-world contexts other than shopping [44]. Generally, consumers depend on slow, serial search processes [45]. The presence of branded products and previous online shopping experiences can facilitate their search. Thus, when they have to make purchase decisions in a short time frame or if they intend to purchase renowned products, they tend to simplify their search on shopping websites. Clement et al. [6] assumed that a comprehensive understanding of product catalogs and experiences of shopping at physical stores can expedite product searches, although their findings showed that consumer product searches in brick-and-mortar contexts were facilitated not by their familiarity with product catalogs, but by their understanding of the way products were displayed in-store. However, this study argues that product catalogs on shopping websites differ from those of physical stores; hence, they might facilitate online product searches. Accordingly, Hypotheses 4 and 5 were formulated as follows: 
Hypotheses (H4). Familiarity with product catalogs on shopping websites can reduce product search time during shopping.

Hypotheses (H5). Experience using other shopping websites can reduce product search time during shopping.

\section{Methods}

We aimed to understand the effect of time pressure on consumer browsing behavior and attention level with an EEG (electroencephalogram) biosensor cap with regard to branded products on online shopping website. To verify our hypotheses, we conducted a laboratory study on a real-world website. Participants were recruited and assigned to two time-pressure levels (the presence or absence of time-pressure situations). They were assigned a purchasing task and instructed to browse on Taobao (a famous Chinese shopping website). We used an EEG biosensor cap to track the attention level of the participants as they browsed products on the webpage. Upon completion of the experiment, the participants were given a $\$ 20$ gift card as our token of appreciation for their time and effort.

\subsection{Electroencephalogram (EEG) Technique}

According to the traditional model of control, physiological systems self-regulate their activity to preserve steadiness by reducing fluctuations around a homeostatic equilibrium point. By contrast with this view, a wide bulk of evidence has recently been provided that several physiological time signals exhibit intrinsic fractal fluctuations. Indeed, heartbeat, respiration, gait rhythm, dynamics of neurotransmitter release, electromyography, and brain activity reveal similar temporal patterns over multiple time scales [46]. In an active postsynaptic neuron, a negative voltage between neural dendrites and other locations along the neuron is generated. Within a small brain compartment in which dendritic structure are parallel and follow a main direction, such a situation can be modelled as a current dipole generating an electromagnetic field. Both electrical potentials and magnetic fields, generated from the dipole in this compartment, can be measured non-invasively by sensors located on or close to the scalp. The technology that measures electrical potentials is called electroencephalography [47].

In this study, a light NeuroSky EEG biosensor cap (i.e., MindWave Mobile as shown in Figure 1) was used for measuring the attention and meditation levels of shoppers. The MindWave Mobile is a portable, wireless hardware cap developed by NeuroSky Company (Taipei, Taiwan). Crowley et al. [48] have evaluated a similar NeuroSky EEG biosensor cap (i.e., Mindset) to measure the attention and meditation levels of a subject in practice. MindWave Mobile outputs 12 bit raw-brainwaves $(3-100 \mathrm{~Hz})$ with a sampling rate of $512 \mathrm{~Hz}$ and EEG power spectra (alpha, beta, etc.). The detected waves were interpreted by eSense ${ }^{\mathrm{TM}}$ (NeuroSky's proprietary algorithm for characterizing mental states, Windows version v1.2.3) to indicate each subject's mental state when they were shopping online. For each different mental state (i.e., attention, meditation), the meter value from $\mathrm{eSense}^{\mathrm{TM}}$ is reported on a relative scale of 1 to 100 . On this scale, a value between 40 and 60 at any given moment in time is considered "neutral". A value from 60 to 80 is considered "slightly elevated", and may be interpreted as levels being possibly higher than normal. Values from 80 to 100 are considered "elevated". Similarly, a value between 20 and 40 indicates "reduced", while a value between 1 and 20 indicates a "strongly lowered" level of each different mental state.

In addition, meditation is considered as a promising technique for body and mind regulation. Meditation plays an important role at physical, mental, and spiritual levels. EEG measures the brain activity useful to recognize the emotional states. EEG has excellent resolution at the millisecond scale, and is superior to positron emission tomography (PET) and functional magnetic resonance imaging (fMRI) [49]. Crowley et al. [48] have evaluated the use of NeuroSky's Mindset headset to measure the attention and meditation levels of a subject in practice. Thus, analyzing shoppers' attention and meditation level when shopping under time pressure or not is straightforward. 


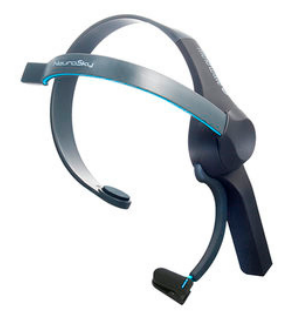

Figure 1. MindWave Mobile, NeuroSky.

\subsection{Subjects and Tasks}

To address the research questions, a sample of 30 participants who had online shopping experience was recruited via convenience sampling. While wearing an EEG cap, the subjects performed tasks of product purchases on Taobao. They used the catalogs, listed recommendations, and keywords provided by the website and purchased products of their preference. The experiment was conducted in a quiet laboratory with a laptop computer to ensure that the subjects would not be disturbed. The EEG biosensor cap was connected with Bluetooth to a laptop to record subjects' brainwaves and obtain experimental data.

\subsection{Experimental Procedure}

An Institutional Review Board (IRB) proof was conducted (Approval No.: NCKU-HREC-E104-101-2) before this experiment. All subjects were asked to complete a questionnaire regarding their mental and physical states and whether they had ever shopped on any shopping websites, and to sign an informed consent form.

To reduce any discomfort from wearing the cap, which would affect the experimental results, the subjects were given some time (approximately $3 \mathrm{~min}$ ) at the beginning of the experiment to accustom themselves to the cap. During the experiment, each subject purchased 10 specific items in odd and even number from the 20 best-selling products sold on Taobao (Figure 2) while under time pressure (10 $\mathrm{min}$ ) and not under time pressure (unlimited time) conditions. The sample size was comparable with in-store studies of shopper navigation and the number of purchases was also comparable with that used in past in-store work. Table 1 presents the top 20 products on Taobao shopping website at the time of the experiment and their respective item numbers. This experiment was aimed at investigating whether the subjects focused on certain products or renowned brands when under time pressure. The renowned brands were defined according to the American Marketing Association, World Brand Lab and other related websites. The shopper's choices, durations, visual attention and site navigation were recorded using our own designed program. After the experiment, each subject completed a questionnaire regarding the number of years of experience they had in using shopping websites. Data collected from the questionnaire were analyzed to determine whether familiarity with shopping website product catalogs and experience using shopping websites facilitated the subjects' purchase behavior in online shopping.

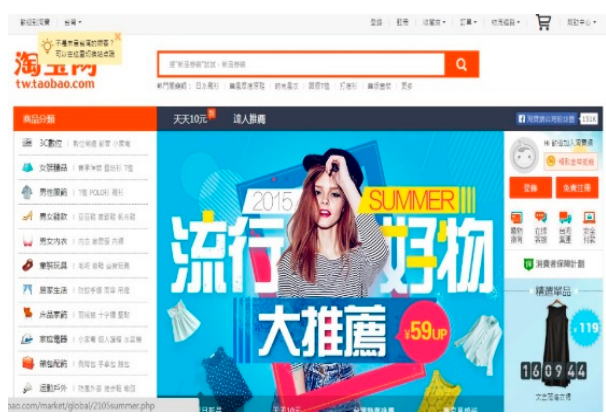

Figure 2. Taobao home page. 
Table 1. Top 20 products on Taobao and assigned items.

\begin{tabular}{ccc}
\hline Condition & Under Time Pressure & Not Under Time Pressure \\
\hline Item1 & Sweater coat & Dress \\
Item2 & Women's footwear & Mobile phone \\
Item3 & Shirt & Sweater \\
Item4 & Windbreaker & Children's apparel \\
Item5 & Wallpaper & iPhone \\
Item6 & Wall sticker & Purse \\
Item7 & Men's footwear & Cotton-padded clothing \\
Item8 & Thermos & Dr. Martens boots \\
Item9 & Spring and autumn dresses & Spring and autumn women's bottoming shirt \\
Item10 & Watch & Tablet computer \\
\hline
\end{tabular}

\section{Results}

To test the proposed hypotheses, the experimental data on the subjects' online shopping behavior were analyzed through the paired $t$-test to compare the test outcomes between different test conditions and attention types. Descriptive statistics and paired $t$-test results are shown below.

\subsection{Demographic Data}

The demographic data in Table 2 show that the sample comprised 15 men and 15 women who had experience using shopping websites. The subjects were 21-30 years old and all held a bachelor's degree. Most of the subjects had extensive experience using the Internet ( $>10$ years, $83.4 \%$; 5-10 years, $13.3 \%$; <1 year, 3.3\%) and reported that they had used Ruten $(86.7 \%)$, Yahoo! (80\%), PChome (53.3\%), Taobao (26.7\%), and Amazon (10\%) for online shopping. Regarding the frequency with which they used online shopping websites, $46.8 \%$ reported that they used them 1-5 times per year, $26.6 \%$ reported using them 5-10 times per year, and $26.6 \%$ used them $>10$ times per year. For the number of years of experience using online shopping websites, $50 \%$ had $1-5$ years of experience, $33.3 \%$ had $5-10$ years of experience, and $16.7 \%$ had $>10$ years of experience.

\subsection{T-Test Results}

\subsubsection{Shoppers Viewed Fewer Products under Time Pressure}

The mean of products viewed by all 30 subjects was 28.78 (standard deviation (SD): \pm 11.986 ), and the mean time spent on purchasing the 10 assigned product items was $9.097 \mathrm{~min}$ (SD: \pm 3.9072 ). An independent t-test revealed a non-significant gender difference in the number of products viewed, as shown in Table 3, where SD stands for standard deviation and SE stands for standard error. The F-value was non-significant at $0.958>0.05$ for the under time-pressure condition and at $0.960>0.05$ for the not under time-pressure condition. Thus, an equal-variances test was conducted for the under time-pressure condition $(t=0.323, p=0.749>0.05)$ and the not under time-pressure condition $(t=-0.643, p=0.525>0.05)$. No significant difference was observed between the numbers of products viewed by the male and female participants, regardless of the condition. Accordingly, the data were subjected to further analysis.

Table 4 tabulates the descriptive statistics for the number of products viewed under both conditions, and Table 5 presents the paired $t$-test results. The $p$ value was 0.001 indicates a significant difference in the number of products viewed between two conditions; specifically, the subjects under time-pressure condition viewed more products. 
Table 2. Demographic statistics.

\begin{tabular}{|c|c|c|c|}
\hline Item & Variable & $N$ & $\%$ \\
\hline \multirow{2}{*}{ Sex } & $M$ & 15 & 50 \\
\hline & $\mathrm{F}$ & 15 & 50 \\
\hline Age & $21-31$ & 30 & 100 \\
\hline $\begin{array}{l}\text { Highest level of } \\
\text { education }\end{array}$ & Graduate & 30 & 100 \\
\hline \multirow{3}{*}{$\begin{array}{l}\text { How many years of } \\
\text { experience do you have } \\
\text { using the Internet? }\end{array}$} & $<1$ year & 1 & 3.3 \\
\hline & 5-10 years & 4 & 13.3 \\
\hline & $>10$ years & 25 & 83.4 \\
\hline $\begin{array}{l}\text { Have you shopped } \\
\text { online before? }\end{array}$ & Yes & 30 & 100 \\
\hline \multirow{5}{*}{$\begin{array}{l}\text { Which of these online } \\
\text { shopping website(s) } \\
\text { have you purchased } \\
\text { items from before? }\end{array}$} & Ruten & 26 & 86.7 \\
\hline & PChome & 16 & 53.3 \\
\hline & Yahoo & 24 & 80 \\
\hline & Taobao & 8 & 26.7 \\
\hline & Amazon & 3 & 10 \\
\hline \multirow{3}{*}{$\begin{array}{l}\text { How frequently do you } \\
\text { use shopping websites } \\
\text { each year? }\end{array}$} & $1-5$ times & 14 & 46.8 \\
\hline & 5-10 times & 8 & 26.6 \\
\hline & $>10$ times & 8 & 26.6 \\
\hline \multirow{3}{*}{$\begin{array}{l}\text { How many years of } \\
\text { experience do you have } \\
\text { using shopping } \\
\text { websites? }\end{array}$} & $1-5$ times & 15 & 50 \\
\hline & 5-10 times & 10 & 33.3 \\
\hline & $>10$ times & 5 & 16.7 \\
\hline
\end{tabular}

Table 3. Independent $t$-test results for gender differences in the number of products viewed.

\begin{tabular}{cccccccc}
\hline Independent Variable & $\boldsymbol{n}$ & Mean & SD & SE & $d f$ & $t$ & $p$-Value \\
\hline Under time pressure (male) & 15 & 23.867 & 4.580 & 1.182 & 28 & 0.323 & 0.749 \\
Under time pressure (female) & 15 & 23.333 & 4.466 & 1.153 & 28 & & \\
Not under time pressure (male) & 15 & 32.200 & 14.178 & 3.660 & 28 & -0.643 & 0.525 \\
Not under time pressure (female) & 15 & 35.733 & 15.867 & 4.097 & & & \\
\hline
\end{tabular}

Table 4. Descriptive statistics for the number of products viewed.

\begin{tabular}{ccccccc}
\hline Condition & $\boldsymbol{n}$ & Mean & Median & Min & Max & SD \\
\hline $\begin{array}{c}\text { Under time pressure } \\
\begin{array}{c}\text { Not under time } \\
\text { pressure }\end{array}\end{array}$ & 30 & 23.600 & 29 & 14 & 37 & 4.453 \\
& 30 & 33.967 & 22 & 18 & 84 & 14.893 \\
\hline
\end{tabular}

Table 5. Paired $t$-test results for the number of products viewed between two conditions.

\begin{tabular}{cccccc}
\hline Independent Variable & $n$ & Mean & SD & SE & $p$-Value \\
\hline $\begin{array}{c}\text { Under time } \\
\text { pressure-Not under } \\
\text { time pressure }\end{array}$ & 30 & -10.366 & 15.082 & 2.753 & $0.001^{* * *}$ \\
\hline & & & & \\
\hline
\end{tabular}


In addition, regarding the EEG analysis, a paired $t$-test was conducted on the attention and meditation levels of the subjects when shopping under time pressure and not under time pressure conditions; the corresponding descriptive statistics and paired t-test results are presented in Tables 6 and 7 , respectively. The $p$-value for the difference between the attention levels was 0.008 and the difference between the meditation levels was 0.572 (Table 7). These results indicate that under time-pressure and not under time-pressure conditions, the subjects differed significantly in attention but not in meditation. Their attention during online shopping was weaker while under time pressure.

Table 6. Descriptive statistics for attention and meditation levels.

\begin{tabular}{lcccccc}
\hline \multicolumn{1}{c}{ Condition } & $\boldsymbol{n}$ & Mean & Median & Min & Max & SD \\
\hline Under time pressure (attention) & 30 & 46.941 & 52.38 & 33.85 & 60.48 & 6.216 \\
Not under time pressure (attention) & 30 & 50.615 & 53.49 & 37.93 & 64.7 & 6.931 \\
Under time pressure (meditation) & 30 & 56.127 & 58.26 & 46.71 & 64.74 & 4.453 \\
Not under time pressure (meditation) & 30 & 55.702 & 56.94 & 49.2 & 69.04 & 14.893 \\
\hline
\end{tabular}

Table 7. Paired $t$-test results for attention and meditation levels.

\begin{tabular}{lccccc}
\hline \multicolumn{1}{c}{ Independent Variable } & $n$ & Mean & SD & SE & $p$-Value \\
\hline $\begin{array}{l}\text { Under time pressure-Not under time } \\
\text { pressure (attention) }\end{array}$ & 30 & -3.673 & 7.097 & 1.295 & $0.008^{* *}$ \\
$\begin{array}{l}\text { Under time pressure-Not under time } \\
\text { pressure (meditation) }\end{array}$ & 30 & 0.424 & 4.060 & 0.741 & 0.572 \\
\hline
\end{tabular}

** $p<0.01$.

\subsubsection{Shoppers Focused more on Renowned Brands while under Time Pressure}

This section discusses whether shoppers focus more on renowned brands when under time pressure. Of the 10 assigned product items to be purchased, 1.31 products were from renowned brands on average (SD: \pm 0.8658 ). An independent $t$-test revealed a no significant gender difference in the number of branded products purchased (Table 8 ). The $F$-value was not significant at $0.806>0.05$ for the under time-pressure condition and at $0.259>0.05$ for the not shopping under time-pressure condition. Thus, an equal-variances test was conducted for under the time-pressure condition $(t=0.638, p=0.529$ $<0.05)$ and not shopping under time-pressure condition $(t=-0.475, p=0.638>0.05)$. No significant difference was observed between the numbers of branded products purchased by the male and female subjects, regardless of the condition.

Table 8. Independent $t$-test results for gender differences in the number of renowned brands.

\begin{tabular}{lccccccc}
\hline \multicolumn{1}{c}{ Independent Variable } & $\boldsymbol{n}$ & Mean & SD & SE & $d f$ & $\boldsymbol{t}$ & $\boldsymbol{p}$-Value \\
\hline Under time pressure (male) & 15 & 1.067 & 0.883 & 0.228 & \multirow{2}{*}{28} & 0.638 & 0.529 \\
Under time pressure (female) & 15 & 0.867 & 0.833 & 0.215 & & & \\
Not under time pressure (male) & 15 & 1.600 & 0.632 & 0.163 & \multirow{2}{*}{28} & -0.475 & 0.638 \\
Not under time pressure (female) & 15 & 1.733 & 0.883 & 0.228 & & & \\
\hline
\end{tabular}

A paired $t$-test was conducted to examine whether deducting the number of renowned brand products purchased with the under time-pressure condition from those purchased with the not under time-pressure condition would yield a result greater than zero. Descriptive statistics and the paired $t$-test results are shown in Tables 9 and 10, respectively. The $p$-value was 0.001 (Table 10), which indicates a significant difference in the number of renowned brand products purchased between the two conditions; specifically, fewer products were purchased under time pressure. 
Table 9. Descriptive statistics for renowned brand products purchased.

\begin{tabular}{lcccccc}
\hline \multicolumn{1}{c}{ Condition } & $\boldsymbol{n}$ & Mean & Median & Min & Max & SD \\
\hline Under time pressure & 30 & 0.967 & 1 & 0 & 3 & 0.850 \\
$\begin{array}{l}\text { Not under time } \\
\text { pressure }\end{array}$ & 30 & 1.667 & 1 & 0 & 3 & 0.758 \\
\hline
\end{tabular}

Table 10. Paired $t$-test results for the number of products purchased.

\begin{tabular}{cccccc}
\hline Independent Variable & $n$ & Mean & SD & SE & $p$-Value \\
\hline $\begin{array}{c}\text { Under time pressure-Not under time } \\
\text { pressure }\end{array}$ & 30 & -0.7 & 0.987 & 0.180 & $0.001^{* * *}$ \\
\hline & ${ }^{* * *} p<0.001$.
\end{tabular}

4.2.3. Familiarity with Product Catalogs on Shopping Websites Facilitated Product Searches during Shopping

When shopping with the not under time-pressure condition, the subjects were asked to purchase five products under the condition that the subjects were unfamiliar with the product catalogs, and five others under the condition that the subjects were familiar with the product catalogs. The products are shown in Table 11. The amount of time that the male (ID a, b, c, .. with symbol $\bullet$ ) and female (ID A, B, C, ... with symbol $\mathbf{\Delta}$ ) subjects spent on product searches is depicted by Figure 3 , in which the $\mathbf{x}$-axis denotes the amount of time spent searching for products in catalogs that the subjects were familiar with, and the $y$-axis represents the amount of time they spent searching for products in catalogs that they were unfamiliar with.

Table 11. Taobao's best-selling products purchased not under time pressure.

\begin{tabular}{ccc}
\hline Condition & Catalog Unfamiliarity & Catalog Familiarity \\
\hline 1 & Dress & Purse \\
2 & Mobile phone & Cotton-padded clothing \\
3 & Sweater & Dr. Martens boots \\
4 & Children's apparel & Spring and autumn women's bottoming shirt \\
5 & iPhone & Tablet computer \\
\hline
\end{tabular}

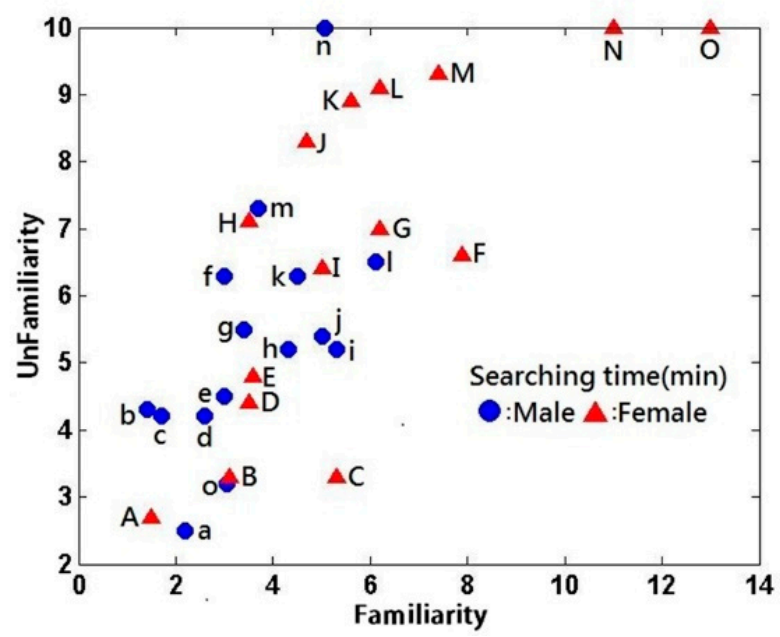

Figure 3. Product search time in minutes.

An independent t-test was conducted to determine the significance level of the gender difference in the product search times (Table 12). The F-value was not significant at $0.057>0.05$ for catalog 
familiarity and at $0.075>0.05$ for catalog unfamiliarity. Thus, an equal-variances test was conducted for the catalog familiarity condition $(t=-2.550, p=0.017<0.05)$ and the catalog unfamiliarity condition $(t=-1.745, p=0.092>0.05)$. A significant gender difference was observed in the product search times under the catalog familiarity condition but not under the catalog unfamiliarity condition. Accordingly, the data were subjected to further analysis.

Table 12. Independent $t$-test results for gender differences in the product search times.

\begin{tabular}{cccccccc}
\hline Independent Variable & $\boldsymbol{n}$ & Mean & SD & SE & $d f$ & $\boldsymbol{t}$ & $\boldsymbol{p}$-Value \\
\hline Familiarity (male) & 15 & 3.649 & 1.386 & 0.357 & \multirow{2}{*}{28} & -2.550 & 0.017 \\
Familiarity (female) & 15 & 5.901 & 3.127 & 0.807 & & & \\
Unfamiliarity (male) & 15 & 5.415 & 1.796 & 0.463 & 28 & -1.745 & 0.092 \\
Unfamiliarity (female) & 15 & 6.847 & 2.620 & 0.676 & & & \\
\hline
\end{tabular}

A paired $t$-test was conducted to examine whether deducting the product search time under the catalog unfamiliarity condition from that under the catalog familiarity condition would yield a result greater than 0 . Descriptive statistics and the paired $t$-test results for the product search times are presented in Tables 13 and 14, respectively. The $p$-value was 0.000 (Table 14), which indicates a significant difference in the product search times between the catalog familiarity and unfamiliarity conditions; specifically, longer search times were observed under the catalog unfamiliarity condition as expected.

Table 13. Descriptive statistics for the product search times.

\begin{tabular}{ccccccc}
\hline Condition & $\boldsymbol{n}$ & Mean & Median & Min & Max & SD \\
\hline Unfamiliarity & 30 & 6.331 & 5.50 & 2.59 & 10.66 & 2.295 \\
Familiarity & 30 & 4.998 & 3.10 & 1.44 & 13.53 & 2.819 \\
\hline
\end{tabular}

Table 14. Paired $t$-test results for the product search times (familiarity vs. unfamiliarity).

\begin{tabular}{cccccc}
\hline Independent Variable & $\boldsymbol{n}$ & Mean & SD & SE & $p$-Value \\
\hline Unfamiliarity-Familiarity & 30 & 1.356 & 1.789 & 0.326 & $0.000^{* * *}$ \\
\hline \multicolumn{3}{c}{${ }^{* * *} p<0.001}$.
\end{tabular}

Moreover, the number of product web pages surfed under the catalog familiarity condition was compared with that under the catalog unfamiliarity condition (Figure 4). An independent $t$-test was used to determine the significance level of the gender difference in the number of product web pages surfed (Table 15). The F-value was non-significant at $0.733>0.05$ under the catalog familiarity condition and at $0.511>0.05$ under the catalog unfamiliarity condition. Thus, an equal-variances test was conducted for the catalog familiarity condition $(t=0.173, p=0.864>0.05)$ and catalog unfamiliarity condition $(t=-1.434, p=0.163>0.05)$. No significant gender difference was observed in the number of product web pages surfed between the male and female subjects, regardless of the catalog familiarity or unfamiliarity condition. Accordingly, the data were subjected to further analysis.

Table 15. Independent $t$-test results for gender in the number of web page surfed.

\begin{tabular}{cccccccc}
\hline Independent Variable & $\boldsymbol{n}$ & Mean & SD & SE & $d f$ & $\boldsymbol{t}$ & $\boldsymbol{p}$-Value \\
\hline Familiarity (male) & 15 & 15.467 & 8.854 & 2.286 & \multirow{2}{*}{28} & 0.173 & 0.864 \\
Familiarity (female) & 15 & 15.000 & 5.567 & 1.437 & & & \multirow{2}{*}{0.163} \\
Unfamiliarity (male) & 15 & 16.733 & 8.655 & 2.234 & \multirow{2}{*}{28} & -1.434 & \\
Unfamiliarity (female) & 15 & 21.400 & 9.155 & 2.364 & & & \\
\hline
\end{tabular}




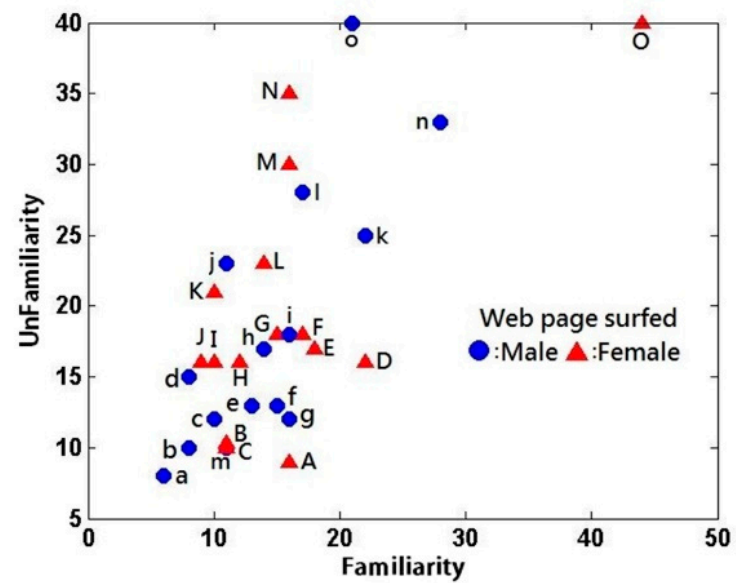

Figure 4. Number of product web pages surfed (familiarity vs. unfamiliarity).

The number of product web pages surfed was compared between the catalog familiarity and unfamiliarity conditions. The descriptive statistics and paired $t$-test results are presented in Tables 16 and 17 , respectively. The $p$-value was 0.004 , which indicates a significant difference in the number of product web pages surfed between the two conditions; specifically, more pages were surfed under the catalog unfamiliarity condition as expected.

Table 16. Descriptive statistics for the number of product web page surfed.

\begin{tabular}{ccccccc}
\hline Condition & $\boldsymbol{n}$ & Mean & Median & Min & Max & SD \\
\hline Unfamiliarity & 30 & 19.067 & 9.50 & 8 & 40 & 9.070 \\
Familiarity & 30 & 15.233 & 13.50 & 6 & 44 & 7.271 \\
\hline
\end{tabular}

Table 17. Paired $t$-test results for the number of web page surfed.

\begin{tabular}{cccccc}
\hline Independent Variable & $n$ & Mean & SD & SE & $p$-Value \\
\hline Unfamiliarity-Familiarity & 30 & -3.833 & 6.664 & 1.216 & $0.004^{* *}$ \\
\hline \multicolumn{7}{c}{${ }^{* *} p<0.01}$.
\end{tabular}

Testing for significant differences in attention and meditation levels between the catalog familiarity and unfamiliarity conditions was undertaken. The descriptive statistics and paired $t$-test results are presented in Tables 18 and 19, respectively. The $p$-value for attention was 0.007 and the $p$-value for meditation was 0.946 (in Table 19). These results indicate a significant difference between the catalog familiarity and unfamiliarity conditions in the attention levels of the subjects but not in their meditation levels. Notably, the subjects with catalog unfamiliarity demonstrated weaker attention during product searches than those with catalog familiarity.

Table 18. Descriptive statistics for attention and meditation.

\begin{tabular}{ccccccc}
\hline Condition & $\boldsymbol{n}$ & Mean & Median & Min & Max & SD \\
\hline Familiarity (attention) & 30 & 52.914 & 55.44 & 41.71 & 71.63 & 8.741 \\
Unfamiliarity (attention) & 30 & 48.797 & 51.30 & 32.94 & 58.9 & 6.464 \\
Familiarity (meditation) & 30 & 56.169 & 55.44 & 48.01 & 72.28 & 5.143 \\
Unfamiliarity (meditation) & 30 & 56.241 & 58.82 & 49.16 & 66.44 & 4.885 \\
\hline
\end{tabular}


Table 19. Paired $t$-test results for attention and meditation levels.

\begin{tabular}{cccccc}
\hline Independent Variable & $n$ & Mean & SD & SE & $p$-Value \\
\hline Unfamiliarity-Familiarity (attention) & 30 & 4.117 & 7.820 & 1.427 & $0.007^{* *}$ \\
Unfamiliarity-Familiarity (meditation) & 30 & -0.072 & 5.791 & 1.057 & 0.946 \\
\hline & ${ }^{* *} p<0.01$.
\end{tabular}

\subsubsection{More Experience Using Shopping Websites Facilitated Product Search}

Before the experiment, all the subjects were asked to complete a questionnaire that included items about their number of years of experience using shopping websites. A survey of Taiwanese online shoppers conducted by Foreseeing Innovative New Digiservices (which operates under the Institute for Information Industry, a non-governmental organization promoting the development of Taiwan's information industry) revealed that most shoppers have more than 5 years of online shopping experience. Accordingly, in this study, those with more than 5 years of experience were defined as "more experienced online shoppers," and those with less than 5 years of experience were defined as "less experienced online shoppers." In this survey of our participants, the more experienced online shoppers spent an average of $9.93 \mathrm{~min}$ (SD: \pm 4.2937 ), compared with their less experienced counterparts, who spent an average of $11.75 \mathrm{~min}$ (SD: \pm 4.8990$)$ in purchases. Therefore, the null hypothesis is "There is no significant difference in the product search times between more experienced and less experienced online shoppers." Table 20 presents the independent $t$-test results for the product search times between the more experienced and less experienced online shoppers. The test statistic was $t=1.073$ and $p=0.293>0.05$. Therefore, the difference in product search times between the more experienced and less experienced online shoppers was not significant.

Table 20. Independent $t$-test results for the product search times.

\begin{tabular}{cccccccc}
\hline Independent Variable & $\boldsymbol{n}$ & Mean & SD & SE & $d f$ & $t$ & $p$-Value \\
\hline Less experienced shoppers & 16 & 11.754 & 4.899 & 1.224 & \multirow{2}{*}{28} & \multirow{2}{*}{1.073} & 0.293 \\
More experienced shoppers & 14 & 9.937 & 4.293 & 1.147 & & & \\
\hline
\end{tabular}

\section{Discussion and Implications}

After experiment and hypothesis testing, the findings of this study and their implications are summarized as follows.

\subsection{Under Time Pressure, Shoppers Focus on Fewer Products during Online Shopping}

This finding corresponds with previous studies that have shown that shoppers under time pressure tend to hasten their product selection [50,51], expedite their information searches to reduce time spent processing information [25,36], or concentrate on specific brands and desired product attributes when making purchase decisions [18]. Therefore, comparing the results of the previous studies revealed that online shopping behavior under time pressure has not changed much despite the rapid development of the Internet and growing use of online shopping services over the past decade.

Moreover, Iyer [22] showed that customers with sufficient time for shopping but without shopping lists are inclined to make more purchases. Dhar and Nowlis [50] noted that online stores typically offer discounts for rush purchases. Ahituv et al. [13] suggested that under time pressure, decision makers tend to make decisions and execute decision-making strategies through simple means. Discounts promote consumption and, under time constraints, they can prompt quick purchase decisions. Most shopping website operators offer limited-edition products that can only be purchased by applying for a membership within certain periods. Such promotional campaigns, which feature a limited number of products, can prompt shoppers to hasten their product searches and make quick purchase decisions. 
Shopping website operators can launch similar campaigns to encourage consumers shopping under time pressure, such as promotions and special offers, to boost sales and reduce the server load.

\subsection{Shoppers Engaging in Online Shopping Focus More on Renowned Brand Products When Not under Time Pressure}

When shopping under time pressure, specific characteristics of products typically draw the attention of consumers [26,36,52]. New characteristics added to a product often become essential factors that affect consumers' purchase decisions $[53,54]$. Distinctiveness exerts stronger effects on product purchase decisions when consumers are under time pressure [50]. Contrary to these previous studies, this study found that subjects did not pay more attention to renowned brand products when they were under time pressure. The result indicated that the renowned brands characteristic of a product are not equivalent to product distinctiveness or novelty, which attract consumer attention under time pressure. In other words, only when a consumer is not under time pressure do they have adequate time to select renowned brand products. This can be attributed to renowned brand products typically being high-priced, prompting consumers to give more consideration prior to making a purchase than they would give on non-renowned brand products. Moreover, Mitchell and Greatorex [55] found that consumers tend to shop at reputable stores to reduce the risk of purchasing low-quality products. Huang et al. [56] showed that brand awareness is crucial for reducing purchase risk. Accordingly, shoppers tend to pay more attention to searching for renowned brand products when not under time pressure to reduce this risk. According to the aforementioned arguments, shopping website operators can sell more renowned brand products during non-promotional periods to encourage consumption and improve customer trust. They can also offer their own-brand products during their time-limited promotions to boost their profits.

\subsection{Under Time Pressure, Shoppers Engaging in Online Shopping are Less Attentive}

The EEG measurement results of this study in Section 4.2.1 reveal that shoppers engaging in online shopping are more attentive when not under time pressure, probably because they adopt the depth strategy under this condition, enabling them to focus on the content and depth of products they view [57]. Thus, shopping website operators are suggested to improve the content and depth of their products during non-promotional periods to enhance consumer trust and approval indirectly. They can also encourage changes in consumer behavior through promotional activities, which can prompt shoppers to process information more quickly [27].

\subsection{Catalog Familiarity Reduces Product Search Times}

Hoque and Lohse [58] found that user-friendly user interfaces can facilitate product searches. Sharpe and Staelin [59] observed that people typically prefer spending less time on familiarizing themselves with the layout of a website. This study showed that consumers familiar with product catalogs of a website spend less time on product searches; this finding accords with those of previous studies in a brick-and-mortar store. Mccarthy and Aronson [60] suggested that browsing functionality on webpages should be designed in a manner that renders the pages easy to navigate. Elliott and Speck [61] remarked that convenient browsing, simple interfaces, and well-organized frameworks of websites can enhance operation ease of use and improve user experience. Other authors have identified that consumers may leave a website quickly if they felt the information was useless [62] or had to complete a hard task online [63]. To avoid this unwanted outcome, shopping website operators should avoid making substantial changes to their user interfaces; such changes can confuse consumers, lengthening their product search times. If the operators intend to refine their websites while reducing the likelihood of deterring customers, they should consider hosting online scavenger hunt-type games so that participants can accustom themselves to the product catalogs on the websites. 


\subsection{Shoppers Unfamiliar with Product Catalogs on Shopping Websites are Less Attentive}

Numerous people base their decisions on their past actions $[64,65]$ and inevitably repeat those actions. In psychology, this type of behavior is known as "familiarity" [66]. Soderlund [67] and Payne et al. [68] have argued that familiarity with the shopping environment affects purchase intention; specifically, shoppers with higher familiarity with the environment are more likely to make purchases [69,70] and choose products [71,72]. In familiar shopping environments, shoppers depend on their long-term memory; by contrast, in unfamiliar environments, they rely largely on external messages such as visual stimuli [73]. Moreover, stimuli in unfamiliar environments can attract attention [74], and shoppers at brick-and-mortar stores they are unfamiliar with are highly attentive during shopping [75]. However, the EEG measurement results of this study indicate that shoppers familiar with product catalogs on shopping websites are more attentive during shopping, which is different from Garling et al. [73] and Ashby et al. [76]. Shopping on websites is different from in brick-and-mortar stores. Thus, how consumer attention is affected during online shopping necessitates further research. According to these findings, shopping website operators can retain the original layout of their product catalogs to focus consumer attention ontheir products, which can subsequently facilitate more immediate purchases.

\subsection{Product Search Times are Not Significantly Shorter for More Experienced Shoppers}

Whereas Clement et al. [6] showed that shoppers with more brick-and-mortar shopping experience are more efficient at product searches, this study found no notable reduction in product search times among the more experienced online shoppers. These findings are perhaps due to the differences between the physical and virtual shopping environments. Furthermore, Daly [77] noted that positive attitudes and satisfaction strongly affect online shopping intentions. Swaminathan et al. [78], Deighton [79], and Lepkowska-White et al. [80] have maintained that significant browsing convenience can make information searches easier on websites and improve their popularity. Jin and Park [81] found that less experienced online shoppers have higher perceived risks of shopping websites, whereas their more experienced counterparts tend to focus on the services offered by the websites. They also asserted that service quality becomes increasingly critical for consumers as their transaction relationships with sellers mature. Thus, website operators can improve the security and service quality of their websites (instead of investigating whether their customers have shopped elsewhere online) to strengthen their customer relations and attract new business.

\section{Conclusions}

This study investigated the behavior of consumers shopping online under time pressure, hypothesizing that (1) shoppers under time pressure focus on renowned brand products and are attentive, (2) shoppers with more online shopping experience are more efficient at shopping, and (3) familiarity with product catalogs facilitates product searches. However, the results show that shoppers under time pressure view fewer products and those not under time pressure focus on renowned brand products. In addition, shoppers are less attentive when under time pressure. Moreover, more online shopping experience does not significantly reduce product search times, indicating that the presence of renowned brand products on online shopping websites can lower shoppers' perceived product risks. Shoppers unfamiliar with product catalogs on shopping websites are less attentive. Furthermore, shoppers under time pressure tend to hasten their purchase decisions and browse fewer product pages. The findings and implications of this study may contribute to relevant academic research and online shopping businesses.

Author Contributions: Conceptualization, D.-H.S.; Formal analysis, K.-C.L.; Investigation, K.-C.L.; Methodology, D.-H.S.; Project administration, D.-H.S.; Validation, K.-C.L. and P.-Y.S.; Writing, review and editing, P.-Y.S. 
Acknowledgments: IRB protocol approval number of this study is NCKU HREC-E-104-101-2 (5/7/2015) at Taiwan. (IRB stands for Institutional Review Board. IRBs review and monitor how a research study will be conducted to ensure the study does not cause unreasonable risks to participants.)

Conflicts of Interest: The authors declare no conflict of interest.

\section{References}

1. Drucker, P. Managing in the Next Society; Truman Talley Books; St. Martin's Press: New York, NY, USA, 2002.

2. Chatterjee, D.; Grewal, R.; Sambamurthy, V. Shaping up for e-commerce: Institutional enablers of the organizational assimilation of web technologies. MIS Q. 2002, 26, 65-89. [CrossRef]

3. Miller, G.A. The magical number seven plus or minus two. Psychol. Rev. 1956, 63, 81-97. [CrossRef] [PubMed]

4. Petty, R.E.; Cacioppo, J.T.; Schumann, D. Central and peripheral routes to advertising effectiveness: The moderating role of involvement. J. Consum. Res. 1983, 10, 135-146. [CrossRef]

5. Schwartz, B. The tyranny of choice. Sci. Am. Am. Ed. 2004, 290, 70-75. [CrossRef] [PubMed]

6. Clement, J.; Kristensen, T.; Gronhaug, K. Understanding consumers' in-store visual perception: The influence of package design features on visual attention. J. Retail. Consum. Serv. 2013, 20, 234-239. [CrossRef]

7. Drucker, P.F. Management: Tasks, Responsibilities, Practices; HarperCollins: New York, NY, USA, 1973.

8. Forsythe, S.M.; Shi, B. Consumer patronage and risk perceptions in Internet shopping. J. Bus. Res. 2003, 56, 867-875. [CrossRef]

9. Lin, C.H.; Wu, P.H. How to deal with conflicts? The effect of consumer's subjective time pressure on product attitude judgment and choice. J. Am. Acad. Bus. 2005, 6, 219-224.

10. Vermeir, I.; Kenhove, P.V. The influence of need for closure and perceived time pressure on search effort for price and promotional information in a grocery shopping context. Psychol. Mark. 2005, 22, 71-95. [CrossRef]

11. Rieskamp, J.; Hoffrage, U. Inferences under time pressure: How opportunity costs affect strategy selection. Acta Psychol. 2008, 127, 258-276. [CrossRef]

12. Liu, C.W.; Hsieh, A.Y.; Lo, S.K.; Hwang, Y. What Consumers See when Time Is Running Out: Consumers' Browsing Behaviors on Online Shopping Websites when under Time Pressure. Comput. Hum. Behav. 2017, 70, 391-397. [CrossRef]

13. Ahituv, N.; Igbaria, M.; Sella, A.V. The effects of time pressure and completeness of information on decision-making. J. Manag. Inf. Syst. 1998, 15, 153-172. [CrossRef]

14. Moon, J.; Lee, K. Influence of time pressure on the purchase decision making process in apparel shopping. Res. J. Costume Cult. 2013, 21, 117-128. [CrossRef]

15. Dickson, P.R.; Sawyer, A.G. The price knowledge and search of supermarket shoppers. J. Mark. 1990, 54, 42-53. [CrossRef]

16. Hoyer, W.D. An examination of consumer decision making for a common repeat purchase product. J. Consum. Res. 1984, 11, 822-829. [CrossRef]

17. Shiv, B.; Fedorikhin, A. Heart and mind in conflict: The interplay of affect and cognition in consumer decision making. J. Consum. Res. 1999, 26, 278-292. [CrossRef]

18. Pieters, R.; Warlop, L. Visual attention during brand choice: The impact of time pressure and task motivation. Int. J. Res. Mark. 1999, 16, 1-16. [CrossRef]

19. Olson, J.C.; Jacoby, J. Cue utilization in the quality perception process. In Proceedings of the Third Annual Conference of the Association for Consumer Research, Chicago, IL, USA, 3-5 November 1972; pp. 167-179.

20. Ajzen, I. The theory of planned behavior. Organ. Behav. Hum. Process. 1991, 50, 179-211. [CrossRef]

21. Howard, J.A.S.; Jagdish, N. The theory of buyer behavior (No. 658.834 H6). J. Am. Stat. Inf. 1969. [CrossRef]

22. Iyer, E.S. Unplanned purchasing: Knowledge of shopping environment and time pressure. J. Retail. 1989, 65, 40-57.

23. Davidson, D. A Coherence Theory of Truth and Knowledge. In Truth and Interpretation. Perspectives on the Philosophy of Donald Davidson; LePore, E., Ed.; Blackwell: Oxford, UK, 1986; pp. 307-319.

24. Payne, J.W.; Bettman, J.R.; Johnson, E.J. Adaptive strategy selection in decision making. J. Exp. Psychol. Learn. Mem. Cogn. 1988, 14, 534. [CrossRef]

25. Edland, A.; Svenson, O. Judgment and decision making under time pressure. In Time Pressure and Stress in Human Judgment and Decision Making; Springer: Berlin/Heidelberg, Germany, 1993; pp. 27-40. 
26. Harris, J.; Blair, E. Consumer preference for product bundles: The role of reduced search costs. J. Acad. Mark. Sci. 2006, 34, 506-513. [CrossRef]

27. Ordonez, L.; Benson, L. Decisions under time pressure: How time constraint affects risky decision making. Organ. Behav. Hum. Decis. Process. 1997, 71, 121-140. [CrossRef]

28. Levy, S.A. Flexible and/or rigid control of oculomotor scanning behavior. In Eye Movements: Cognition and Visual Perception; Fisher, D.F., Monty, R.A., Senders, J.W., Eds.; Erlbaum: Hillsdale, NJ, USA, 1981; pp. $299-316$.

29. Rosbergen, E.; Pieters, F.G.M.; Wedel, M. Undirected Visual Attention to Advertising: A Segment-Level Analysis; University of Groningen: Groningen, The Netherlands, 1995.

30. Sherwood, M. Winning the shelf wars. Glob. Cosmet. Ind. 1999, 164, 64-67.

31. Schoormans, J.P.; Robben, H.S. The effect of new package design on product attention, categorization and evaluation. J. Econ. Psychol. 1997, 18, 271-287. [CrossRef]

32. Lee, J.Y.; Gao, Z.; Brown, M.G. A study of the impact of package changes on orange juice demand. J. Retail. Consum. Serv. 2010, 17, 487-491. [CrossRef]

33. Fasolo, B.; Carmeci, F.A.; Misuraca, R. The effect of choice complexity on perception of time spent choosing: When choice takes longer but feels shorter. Psychol. Mark. 2009, 26, 213-228. [CrossRef]

34. Salo, E.; Salmela, V.; Salmi, J.; Numminen, J.; Alho, K. Brain activity associated with selective attention, divided attention and distraction. Brain Res. 2017, 1664, 25-36. [CrossRef]

35. Bettman, J.R.; Luce, M.F.; Payne, J.W. Constructive consumer choice processes. J. Consum. Res. 1998, 25, 187-217. [CrossRef]

36. Zur, H.B.; Breznitz, S.J. The effect of time pressure on risky choice behavior. Acta Psychol. 1981, 47, 89-104.

37. Rettie, R.; Brewer, C. The verbal and visual components of package design. J. Prod. Brand Manag. 2000, 9, 56-70. [CrossRef]

38. Urbany, J.E.; Dickson, P.R.; Kalapurakal, R. Price search in the retail grocery market. J. Mark. 1996, 60, 91-104. [CrossRef]

39. Nordfalt, J. Improving the attention-capturing ability of special displays with the combination effect and the design effect. J. Retail. Consum. Serv. 2011, 18, 169-173. [CrossRef]

40. Keller, K.L. Conceptualizing, measuring, and managing customer-based brand equity. J. Mark. 1993, 5, 1-22. [CrossRef]

41. Keller, K.L. Brand synthesis: The multidimensionality of brand knowledge. J. Consum. Res. 2003, 29, 595-600. [CrossRef]

42. Underwood, R.L.; Klein, N.M. Packaging as brand communication: Effects of product pictures on consumer responses to the package and brand. J. Mark. Theory Pract. 2002, 10, 58-68. [CrossRef]

43. Perkins, D.N. Why Smart People Can be So Stupid; Yale University Press: New Haven, CT, USA, 2002; pp. 64-85.

44. Duncan, J.; Humphreys, G.W. Visual search and stimulus similarity. Psychol. Rev. 1989, 96, 433-458. [CrossRef] [PubMed]

45. Posner, M.I.; Snyder, C.R.; Davidson, B.J. Attention and the detection of signals. J. Exp. Psychol. Gen. 1980, 109, 160-174. [CrossRef]

46. Croce, P.; Quercia, A.; Costa, S.; Zappasodi, F. Circadian Rhythms in Fractal Features of EEG Signals. Front. Physiol. 2018, 9, 1567. [CrossRef]

47. Croce, P.; Zappasodi, F.; Marzetti, L.; Merla, A.; Pizzela, V.; Chiarelli, A. Deep Convolutional Neural Networks for feature-less automatic classification of Independent Components in multi-channel electrophysiological brain recordings. IEEE Trans. Biomed. Eng. 2018, 1. [CrossRef]

48. Crowley, K.; Sliney, A.; Pitt, I.; Murphy, D. Evaluating a Brain-Computer Interface to Categories Human Emotional Response. In Proceedings of the 10th IEEE International Conference on Advanced Learning Technologies, Sousse, Tunisia, 12 April 2010; pp. 276-278.

49. Jadhav, N.; Manthalkar, R.; Joshi, Y. Effect of meditation on emotional response: An EEG-based study. Biomed. Signal Process. Control 2017, 34, 101-113. [CrossRef]

50. Dhar, R.; Nowlis, S.M. The effect of time pressure on consumer choice deferral. J. Consum. Res. 1999, 25, 369-384. [CrossRef]

51. Bell, D.; Corsten, D.; Knox, G. From Point of Purchase to Path to Purchase: How Pre-Shopping Factors Drive Unplanned Buying. J. Mark. 2011, 75, 31-45. [CrossRef]

52. Svenson, O.; Edland, A. Change of Preferences under Time Pressure: Choices and Judgments. Scand. J. Psychol. 1987, 28, 322-330. [CrossRef] 
53. Nowlis, S.M. The effect of time pressure on the choice between brands that differ in quality, price, and product features. Mark. Lett. 1995, 6, 287-295. [CrossRef]

54. Nowlis, S.M.; Simonson, I. The effect of new product features on brand choice. J. Market. Res. 1996, 33, 36-46. [CrossRef]

55. Mitchell, V.W.; Greatorex, M. Risk perception and reduction in the purchase of consumer services. Serv. Ind. J. 1993, 13, 179-200. [CrossRef]

56. Huang, W.Y.; Schrank, H.; Dubinsky, A.J. Effect of brand name on consumers' risk perceptions of online shopping. J. Consum. Behav. 2004, 4, 40-50. [CrossRef]

57. Jacoby, J.; Jaccard, J.J.; Currim, I.; Kuss, A.; Ansari, A.; Troutman, T. Tracing the impact of item-by-item information accessing on uncertainty reduction. J. Consum. Res. 1994, 21, 291-303. [CrossRef]

58. Hoque, A.Y.; Lohse, G.L. An information search cost perspective for designing interfaces for electronic commerce. J. Market. Res. 1999, 36, 387-394. [CrossRef]

59. Sharpe, K.; Staelin, R. Consumption Effects of Bundling: Consumer Perceptions, Firm Actions, and Public Policy Implications. J. Public Policy Mark. 2010, 29, 170-188. [CrossRef]

60. McCarthy, R.V.; Aronson, J.E. Competing in the Virtual World: E-commerce Factors that Affect the Property-Casualty Insurance Industry. Available online: http://aisel.aisnet.org/cgi/viewcontent.cgi?article= $1557 \&$ context=amcis2000 (accessed on 8 July 2019).

61. Elliott, M.T.; Speck, P.S. Factors that affect attitude toward a retail web site. J. Mark. Theory Pract. 2005, 13, 40-51. [CrossRef]

62. Schaffer, E. A better way for web design. Inf. Week 2000, 784, 194.

63. Poddar, A.; Donthu, N.; Wei, Y. Web Site Customer Orientations, Web Site Quality, and Purchase Intentions: The Role of Web Site Personality. J. Bus. Res. 2009, 62, 441-450. [CrossRef]

64. Albarracin, D.; Wyer, R.S. The cognitive impact of past behavior: Influences on beliefs, attitude and future behavior decisions. J. Personal. Soc. Psychol. 2000, 79, 5-22. [CrossRef]

65. Taylor, S.E. On inferring one's attitude from one's behavior: Some delimiting conditions. J. Personal. Soc. Psychol. 1975, 31, 126-131. [CrossRef]

66. Tversky, A.; Kahneman, D. Judgment under uncertainty: Heuristics and biases. Science 1974, 185, $1124-1131$. [CrossRef]

67. Soderlund, M. Customer familiarity and its effects on satisfaction and behavioral intentions. Psychol. Mark. 2002, 19, 861-879. [CrossRef]

68. Payne, C.R.; Hyman, M.R.; Niculescu, M.; Huhmann, B.A. Anthropomorphic responses to new-to-market logos. J. Mark. Manag. 2013, 29, 122-140. [CrossRef]

69. Alter, A.L.; Oppenheimer, D.M. Predicting short-term stock fluctuations by using processing fluency. Proc. Natl. Acad. Sci. USA 2006, 103, 9369-9372. [CrossRef]

70. Huberman, G. Familiarity breeds investment. Rev. Financ. Stud. 2001, 14, 659-680. [CrossRef]

71. Hoyer, W.D.; Brown, S.P. Effects of brand awareness on choice for a common, repeat-purchase product. J. Consum. Res. 1990, 17, 141-148. [CrossRef]

72. Novemsky, N.; Dhar, R.; Schwarz, N.; Simonson, I. Preference fluency in choice. J. Mark. Res. 2007, 44, 347-356. [CrossRef]

73. Garling, T.; Lindberg, E.; Mantyla, T. Orientation in buildings: Effects of familiarity, visual access, and orientation aids. J. Appl. Psychol. 1983, 68, 177-186. [CrossRef] [PubMed]

74. Desimone, R.; Miller, E.K.; Chelazzi, L.; Lueschow, A. Multiple memory systems in the visual cortex. In Cognition Neurosciences; Gazzaniga, M.S., Ed.; MIT Press: Cambridge, MA, USA, 1995; pp. 475-486.

75. Park, C.W.; Iyer, E.S.; Smith, D.C. The effects of situational factors on in-store grocery shopping behavior: The role of store environment and time available for shopping. J. Consum. Res. 1989, 15, 422-433. [CrossRef]

76. Ashby, F.G.; Valentin, V.V.; von Meer, S.S. Differential effects of dopamine-directed treatments on cognition. Neuropsychiatr. Dis. Treat. 2015, 11, 1859-1875. [CrossRef]

77. Daly, K. Corporate performance metrics to top board agendas: With heightened responsibilities and scrutiny, corporate boards are rethinking operations and finding that performance metrics are essential tools. Financ. Exec. 2011, 27, 50-54.

78. Swaminathan, V.; Lepkowska-White, E.; Rao, B.P. Browsers or buyers in cyberspace? An investigation of factors influencing electronic exchange. J. Comput. Mediat. Commun. 1999, 5, 1-23. [CrossRef]

79. Deighton, J.A. The future of interactive marketing. Harvard Bus. Rev. 1996, 74, 151-162. 
80. Lepkowska-White, E.; Page, C.; Youndt, M. Web perception and young consumers: An empirical investigation of factors influencing perceptions of online companies. J. Internet Commer. 2004, 3, 53-77. [CrossRef]

81. Jin, B.; Park, J.Y. The moderating effect of online purchase experience on the evaluation of online store attributes and the subsequent impact on market response outcomes. Adv. Consum. Res. 2006, 33, 203-211.

(C) 2019 by the authors. Licensee MDPI, Basel, Switzerland. This article is an open access article distributed under the terms and conditions of the Creative Commons Attribution (CC BY) license (http://creativecommons.org/licenses/by/4.0/). 